,

\title{
Age- and sex-based differences in functional strength of adults participating in Special Olympics
}

Viviene A. Temple ${ }^{1}$, Pauli Rintala ${ }^{2}$, Shayla Zeitz ${ }^{1}$, Meghann Lloyd ${ }^{3}$, and John T. Foley ${ }^{4}$ Received: $14^{\text {th }}$ September 2020; Accepted: $2^{\text {nd }}$ October 2021; Published: $6^{\text {th }}$ January 2022

\begin{abstract}
Muscular strength is a critical component of physical health. The aim of this cross-sectional study was to examine age- and sex-based differences in functional strength and rates of referral for education in a large international sample of Special Olympics athletes. A total of 30,358 (male $=19,661$ ) adult (2069 years old) athlete functional strength records were utilized from the Special Olympics Healthy Athletes database. Descriptive statistics were computed for the following tests: timed sit to stand, partial sit-up, grip strength, and seated push-up. Analyses of variance with Fisher-Hayter pairwise comparisons generally supported age-related decreases in strength among both males and females in this study. Overall, male participants were stronger than the female participants. However, significantly fewer women were referred for education based on their grip strength scores. The rates of referral for education are a concern regarding core- and leg strength for more than one-third of athletes over the age of 30. These findings suggest that a substantial proportion of Special Olympics athletes would benefit from additional strength and conditioning training.
\end{abstract}

Keywords: Intellectual disability, FUNfitness test battery, education, fitness testing, screening, health, athletes

\section{Introduction}

According to the World Health Organization, muscular strength is a critical component of physical health (World Health Organization, 2020). It is recommended that adults between the ages of 18-64 years engage in a minimum of bi-weekly whole-body strengthening activities to maintain bone health and muscular fitness (World Health Organization, 2020). Activities of daily living such as toileting and dressing, and instrumental activities of daily living such as shopping and cooking, depend on physical strength in both the general population and individuals with an intellectual disability (ID) (Oppewal et al., 2014a, 2015; Taekema et al., 2010). Improving strength reduces the risk of falls (Ishigaki et al., 2014), which are common and can result in injury and hospitalization among individuals with an ID (Cox et al., 2010).

\section{Muscular strength among adults with an intellectual disability}

Despite the importance of strength, individuals with an ID have a lower level of strength than their general-population peers (Cuesta-Vargas et al., 2011; Lahtinen et al., 2007); these lower levels include individuals with an ID who are athletes (Cuesta-Vargas \& Hilgenkamp, 2015). Additionally, among individuals with an ID, there is some evidence that strength decreases with age (Lahtinen et al., 2007; Oppewal et al., 2014b) and that females have lower muscle strength than their male peers (Cuesta-Vargas et al., 2011; Lahtinen et al., 2007; 
Rintala et al., 2016). For example, Cuesta-Vargas and colleagues found that male Special Olympics athletes scored higher than female athletes on the following muscular strength and endurance tests: timed sit to stand, partial sit-up test, seated push-up test, and the hand grip test. Similarly, Lahtinen and others (2007) assessed strength parameters of male and female individuals with an ID longitudinally over their adult lifespan. These authors found that males consistently outperformed females in abdominal strength and endurance. Similar sexbased strength differences were documented more recently in a sample of Nordic Special Olympics athletes (Rintala et al., 2016). However, the small number of female athletes ( $n=$ 79 in the Cuesta-Vargas et al. study, $n=33$ in the Lahtinen et al. study, and $n=15$ in the Rintala et al. study), limits our understanding of sex-related differences.

The connection between strength and functional capacity, and between strength and sports performance in individuals with an ID has been explored in the literature to a certain degree. The available evidence suggests that higher levels of strength are associated with more independent living and enhanced functional capacity (Carmeli et al., 2012; Cowley et al., 2010; Nordgren \& Bäckström, 1971). For example, Cowley and others (2010) found that isometric leg strength of individuals with Down syndrome significantly predicted participants' ability to rise from a chair, ascend and descend stairs, and their gait speed. The relationship between strength and physical capacity in individuals with an ID is corroborated by studies showing improved functional and activities of daily living performance following strength interventions (Carmeli et al., 2012; Cowley et al., 2010). The importance of the ability to independently perform activities of daily living cannot be underestimated in this population as it associated with improvements in quality of life, reduction of stress on family, and caregiver support systems (Oppewal et al., 2014a). Beyond activities of daily living, among athletes with an ID, higher levels of muscular strength and endurance are associated with enhanced sport performance (Franciosi, Baldari, et al., 2010; Franciosi, Guidetti, et al., 2010). By way of illustration, Franciosi, Guidetti and colleagues (2010) found that leg power significantly predicted shooting performance and upper-body strength as well as endurance predicted passing performance among adult male basketball players with an ID.

\section{Special Olympics Healthy Athletes Screening}

Special Olympics International (SOI) is a global not-for-profit sporting organization serving over 5.5 million people with an ID around the world (Special Olympics, 2016). SOI has programs in over 200 countries and offers free health screenings at local, State or Provincial, National, and World Games. SOI is the largest single source of health surveillance data and health services for people with an ID in the world (Special Olympics, 2016) and since 1997 SOI has provided more than 2 million free health screenings (Special Olympics, 2020a). Data from the health screenings are entered into the Healthy Athletes Software (HAS) database. One of the free health screenings offered is FUNfitness.

The FUNfitness health screening was developed by SOI in collaboration with the American Physical Therapy Association to assess Special Olympics athletes' flexibility, strength, balance, and aerobic fitness. These fitness screenings are conducted by trained personnel (i.e., physical therapists, physical therapist trainees or assistants, and exercise specialists) at Special Olympics events using protocols developed by SOI (Special Olympics, 2020b). When the screening identifies areas of need, athletes (plus coaches and family members where appropriate) are provided with one-on-one education and taught exercises that can help improve components of fitness. Further, when educational needs are identified in multiple areas or the individual has lost function over time, the athlete may be referred to a physical therapist or a primary care physician. Special Olympics athletes are 'referred for education' at the FUNfitness screening events when their score for a test falls into a range of 
performance that is deemed in need of remediation to help the athlete achieve better function in that area (Special Olympics, 2020b).

In summary, what we know, based on the current body of literature about individuals with an ID and strength is the following: strength plays an important role in independent living, functional capacity, and fall prevention; strength decreases with age; and strength is lower among women with an ID. However, most research is region-specific and with small sample sizes. Additionally, there is evidence that trends in health-related fitness data among adults with an ID, such as body mass index, do not mirror general population data patterns (Foley et al., 2013). As such, it is important to have population specific data. The aim of this cross-sectional study was to examine age- and sex-based differences in strength metrics and rates of referral for education in a large international sample of Special Olympics athletes. We hypothesized that strength would be lower in the older age bands, and the rate of referral would be higher. Further, we hypothesized that men will be stronger than women.

\section{Materials and Methods}

\section{Data source}

The database for our secondary analyses was the HAS database. The following strength variables from the FUNfitness screening were used in this study: sex, age, event, delegation (country), grip strength, seated push-up, sit to stand-test, and partial sit-up. The Human Research Ethics Boards of University of Victoria and Ontario Tech University provided ethics approval for this secondary analysis (protocol numbers 09-349 and 14-125, respectively).

\section{Measures}

\section{Timed sit to stand test}

The timed sit to stand test measures the ability to stand up from a chair and is a simple and rapid method to quantify functional lower extremity muscle strength (Csuka \& McCarty, 1985; Roldán-Jiménez et al., 2015). The test requires the athlete to sit on a firm straightbacked chair, with feet flat on the floor and hips and knees at a 90-degrees angle. The arms are by the sides with the elbows flexed to 90-degrees throughout the entire test. Without using their arms, an athlete is instructed to stand from sitting and then to sit down again, 10 times as quickly as possible. Time in seconds is recorded to perform the task. An assessor stands beside the athlete during this test in case they lose balance (Special Olympics, 2020b). Performance on the timed sit to stand test is associated with functional limitations. In a representative sample of adults from England, Scotland, and Wales, Kuh and colleagues (2005) demonstrated that the limitations in walking 400 yards and difficulties with stairs increased significantly from bottom tertile to the top third on the 10 times stand test. The 10-times stand test also has strong reproducibility (i.e., 6.8\% variation across testers) among individuals without disabilities (Csuka \& McCarty, 1985) and a high degree of test-retest reliability (Newcomer et al., 1993). Special Olympics athletes are referred for education for their performance on the timed sit to stand test when their time is greater than 20 seconds or they are unable to complete 10 stands (Special Olympics, 2020b).

\section{Partial sit-up test}

The partial sit-up test is used to quantify abdominal muscle strength or endurance. The test involves completing 25 partial sit-ups (or as many as possible) within one minute (Special Olympics, 2020b). The number of partial sit-ups completed is recorded. The athlete is positioned supine on mat with her or his legs flexed to 90-degrees at the hips and knees. The lower legs are placed on a chair or stool. The athlete's arms are positioned straight out in front of the chest with the elbows extended, remaining in this position for the entire test. 
The athlete lifts her or his head and slowly sits up until the base of the scapula clears the floor and then slowly lowers back down again. To help the athlete understand how far to sit up, the assessor provides a target (their hand or a ruler) for the athlete to touch with his or her hands. Researchers who have used electromyography (EMG), has shown that this form of partial sit-up produces good activation of the abdominal muscles (Parfrey et al., 2008) and the modified curl-up test (similar to the partial sit-up test except that the hands slide along the floor to the target) has very acceptable test-retest reliability $(\mathrm{r}=.82)$ (Winnick \& Short, 1998). Special Olympics athletes are referred for education for performance on the partial sit-up test when they are unable to complete 25 sit-ups in one minute (Special Olympics, 2020b).

\section{Grip strength test}

Grip strength was measured using a mechanical dynamometer, which quantifies the tension exerted on a steel spring in kilograms. The testing protocol for the FUNfitness grip strength screening (Special Olympics, 2020b) requires that the athlete sits upright in a straight-backed chair with the elbow bent to 90-degrees. Then, without moving the rest of the body, the athlete squeezes the dynamometer as hard as possible for six seconds. The test is completed three times with each hand (alternating between sides) and the best value for each hand is recorded. Mechanical dynamometers provide both accurate (i.e., recording actual force applied) and reliable (i.e., consistent over time) measures of hand-grip strength (Innes, 1999). Handgrip dynamometry has been shown to be both feasible and reliable among individuals with ID (Hilgenkamp et al., 2012; Salb et al., 2015; Yun et al., 2007). Grip strength has also been shown to have predictive validity of functional decline in mobility among older adults with ID (Oppewal et al., 2014a). Special Olympics athletes are referred for education for performance on the grip strength test when their test score is below the $10^{\text {th }}$ percentile on age-adjusted normative tables for men and for women with ID (Special Olympics, 2020b).

\section{Seated push-up test}

The seated push-up test is a method of assessing strength and endurance of the triceps, shoulder and scapular muscles (Winnick \& Short, 2014). The test involves pushing the body up out of a seated position, holding, and slowly lowering it back to sitting. An athlete is positioned on the floor, legs out straight with heels resting on the floor. The athlete must push her or his body up from the floor on the push-up blocks (circa $10 \mathrm{~cm}$ high) until the elbows are straight, and hold for a maximum of 20 seconds. One practice prior to the test is allowed. The number of seconds that the athlete can hold in the push-up position is recorded (Special Olympics, 2020b). The seated push-up test was designed to test the ability of individuals with physical disabilities to transfer, for example, chair to wheelchair, and to relieve pressure on the buttocks (Short \& Winnick, 2005). From EMG data, the test activates the latissimus dorsi, pectoralis major, and triceps brachii muscles (Anderson et al., 1984), and the muscle activity is $20-30 \%$ greater among women completing this test, compared to men. Athletes are referred for education for performance on the seated push-up test when they cannot lift and support the body for at least 5 seconds (Special Olympics, 2020b). The 5 -second standard was derived from work by Kosiak and Kottke (1990) who advised that relieving pressure on the skin by lifting the body for 5 seconds every 15 minutes is sufficient to prevent pressure sores. 


\section{Data cleaning and statistical analyses}

Initially, 37,034 records of 20 - 69-years-old adult Special Olympics athletes from 173 countries and jurisdictions were available from the SOI HAS database for the period 20022012. Data cleaning procedures, illustrated in Figure 1, were as follows: 1) identify multiple entries for one individual and delete duplicate or redundant entries. This was done using probabilistic matching using sex, birthday, country or state, first name and last name. Scores were given based on the number of items matched. Individuals with a high probability of matching were reviewed. For individuals who had multiple entries in one year or entries over multiple years, the last entry for an individual was retained. 2) Listwise deletions were used when anthropometric, sex, or age data was missing; or and individual was not identified as an athlete. 3) The remaining data were examined and filtered to remove extreme values as identified or values without units of measurement noted (i.e., Kg, lbs). Determining extreme values for grip strength is described in research by Santarossa and colleagues (2017), extreme values for sit-to-stand were values less than 8 seconds. That value was determined by taking the minimum value ( 4 seconds) reported in Bohannon and colleagues (2007) fiverepetition sit-to-stand test and doubling it for the 10-repetition sit-to-stand.

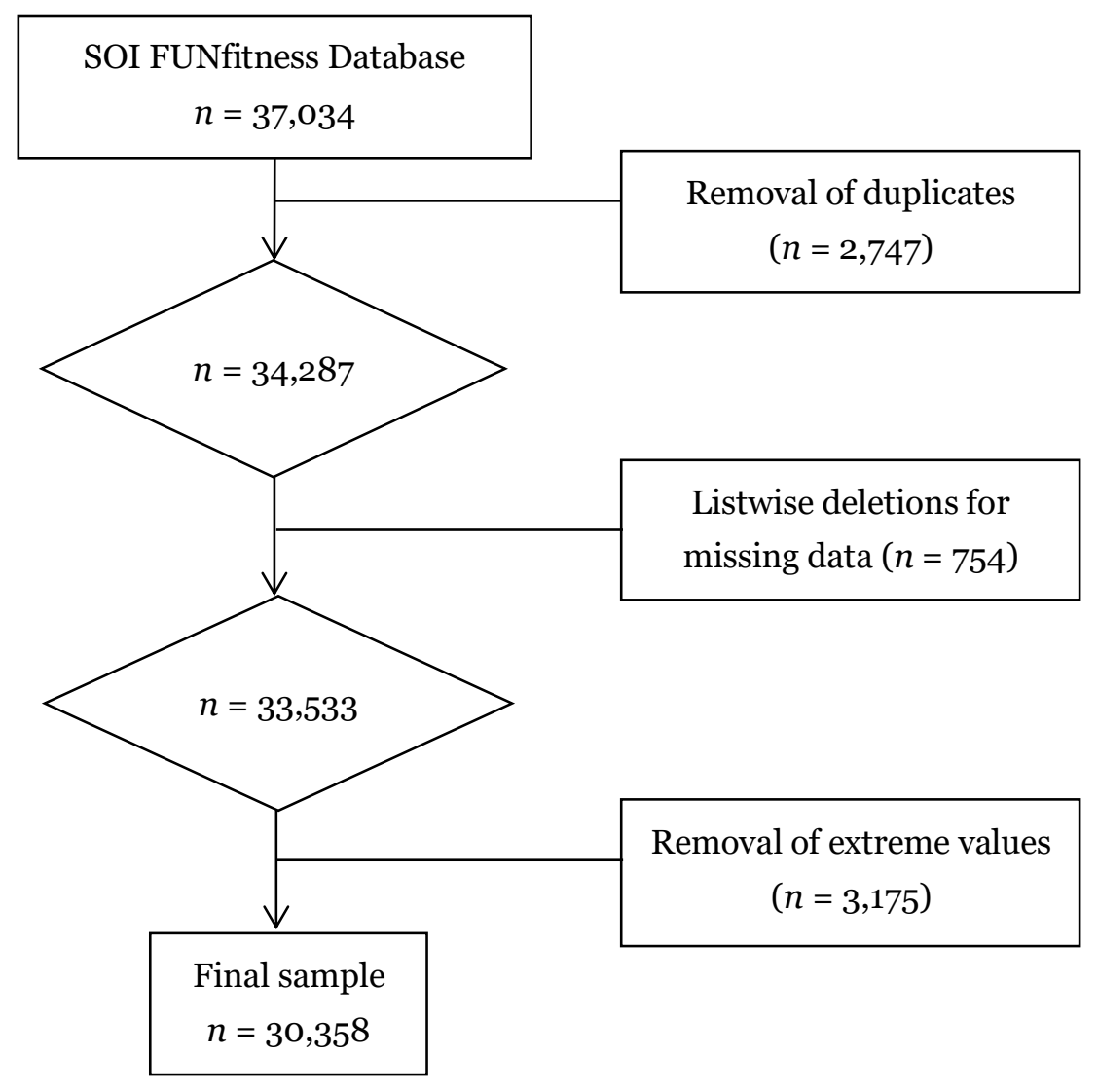

Figure 1. Data cleaning procedure.

Descriptive statistics (mean, standard deviation, range) were computed for each of the screening tests, specifically: Timed sit to stand test (time in seconds), Partial sit-up test (count within 1 minute), Grip strength in kilograms (left and right hand), and Seated pushup test (time in seconds). Sex-based differences were examined using independent sample t-tests and effect sizes were computed using Cohen's $d$. Further, analyses of variance were computed to examine age-related differences for each screening test for men and women separately. Significant main effects were followed-up with post hoc Fisher-Hayter pairwise comparisons (Kirk, 2013). The proportion of participants referred for education for each 
screening test was also computed. Chi-squared test of independence analysis was used to examine the overall difference in the rates of referral for education for men and women by age band, and a further series of chi-squared test of independence were performed to examine sex-based differences in the rate of referral for education between each age band ( 20 - 29 years, $30-39$ years, $40-49$ years, $50-59$ years, and $60-69$ years). Effect sizes were computed using Cramer's $V$. All analyses were performed using Stata Release 15 (Stata Corp, 2017).

\section{Results}

The final sample for this study was $n=30,358$, of whom $n=19,661(64.8 \%)$ were men. Table 1 displays the descriptive statistics for each of the strength measures and provides the $\mathrm{p}$-values and effect sizes arising from the independent $t$-tests performed to examine sexbased strength differences. It is evident that grip strength was significantly lower among women in each age band, as was the seated push-up time except for Special Olympics athletes in the oldest age band (6o - 69-years-old). The timed sit to stand test scores were similar for men and women, except for the youngest age group, where the men were able to complete 10 stands faster than the women $(\mathrm{p}<.001)$. Younger men $(20-29 \mathrm{y}, 30-39 \mathrm{y}$, and $40-49 y$ ) were able to complete more partial sit-ups than the women. There were no sexbased differences in the number of partial sit-ups within the two older age bands.

In Table 2 the age-band comparisons for each of the strength measures are displayed separately for men and women. From Table 2, men were fairly consistent, with statistically significant age-related reductions in partial sit-up, $F(4,15648)=51.17, \mathrm{p}<.001$, right-hand grip strength, $F(4,6259)=7.96$, $\mathrm{p}<.001$, left-hand grip strength, $F(4,6309)=7.56, \mathrm{p}<$ .001 , and seated push-up, $F(4,5494)=29.29, \quad \mathrm{p}<.001$, scores. This trend for men was also evident for the timed sit to stand test, $F(4,821)=7.99, \mathrm{p}<.001$, although this trend appears to plateau from $40-49$ years to $60-69$ years. For women, there were no age-related differences in the timed sit to stand, $F(3,434)=.68, \mathrm{p}=.56$, left-hand grip strength, $F(4$, $3361)=.78, \mathrm{p}=.54$, and right-hand grip strength, $F(4,3298)=1.86, \mathrm{p}=.11$, scores. However, for the seated push-up test, $F(4,2688)=17.91, \quad \mathrm{p}<.001$, there is an age-related decline similar to the men. Women's partial sit-up scores age-related reductions were also statistically significant, $F(4,8492)=7.54, p<.001$. Although these scores are stable between 20 and 39 years, the older age bands have statistically significantly lower scores. However, it should be noted that the actual difference between the youngest and oldest age bands is approximately three partial sit-ups.

The proportion of men and women being referred for education based on their strength scores are presented in Table 3. A 4 x 2 chi-square test of independence analysis was used to determine whether the proportion of SOI participants referred for education in each age band differed by sex. There was a statistically significant overall effect for the model, $\chi^{2}=$ 29.36, $d f=4, p<.001$. For 14 of the 20 age-band comparisons, women were referred for education statistically significantly more often than men (see Table 3). A high proportion of women (89\%) and men (94\%) passed the seated push-up test. Mean scores for women who passed vs. failed the seated push-up test were: grip strength $35.8 \mathrm{~kg}$ vs. $34.2 \mathrm{~kg}$, partial situps 27.8 vs. 24.1 , and timed sit to stand test 18.4 s vs. 20.6 s. Scores for men who passed vs. failed were: grip strength $43.7 \mathrm{~kg}$ vs. $40.6 \mathrm{~kg}$, partial sit-ups $29.8 \mathrm{vs} .24 .7$, and timed sit to stand test $17.4 \mathrm{~s}$ vs. $20.7 \mathrm{~s}$. 
Table 1. Mean scores by age band for each strength test and independent $t$-test sex-based differences.

\begin{tabular}{|c|c|c|c|c|c|c|c|c|c|c|c|c|c|}
\hline \multirow[b]{2}{*}{$\begin{array}{l}\text { Age } \\
\text { group }\end{array}$} & \multirow[b]{2}{*}{ Variable } & \multicolumn{5}{|c|}{ Male } & \multicolumn{5}{|c|}{ Female } & \multirow[b]{2}{*}{$\mathrm{P}$} & \multirow[b]{2}{*}{$\mathrm{d}$} \\
\hline & & $\mathrm{n}$ & Mean & SD & Min & $\operatorname{Max}$ & $\mathrm{n}$ & Mean & $\mathrm{SD}$ & Min & Max & & \\
\hline \multirow[t]{5}{*}{$20-29 y$} & Timed sit to stand test & 536 & 17.4 & 5.7 & 8 & 53 & 252 & 19.4 & 6.7 & 8 & 55 & $<.001$ & 0.32 \\
\hline & Sit-up test & 8,822 & 22.9 & 4.4 & 0 & 25 & 4,670 & 21.9 & 5.4 & 0 & 25 & $<.001$ & 0.20 \\
\hline & Grip strength - Right & 3,572 & 51.9 & 24.4 & 1 & 113 & 1,794 & 33.9 & 14.9 & 2 & 69 & $<.001$ & 0.89 \\
\hline & Grip strength - Left & 3,606 & 50.0 & 23.9 & 1 & 113 & 1,841 & 32.8 & 15.0 & 1 & 69 & $<.001$ & 0.86 \\
\hline & Seated push-up test & 3,230 & 18.3 & 4.4 & 0 & 20 & 1,592 & 16.2 & 6.2 & 0 & 20 & $<.001$ & 0.39 \\
\hline \multirow[t]{5}{*}{$30-39 y$} & Timed sit to stand test & 195 & 18.4 & 6.0 & 8 & 42 & 134 & 19.7 & 7.1 & 9 & 47 & .060 & 0.20 \\
\hline & Sit-up test & 3,835 & 22.5 & 4.7 & 0 & 25 & 2,124 & 21.6 & 5.6 & 0 & 25 & $<.001$ & 0.17 \\
\hline & Grip strength - Right & 1,454 & 51.6 & 24.5 & 2 & 112 & 814 & 35.4 & 16.1 & 3 & 70 & $<.001$ & 0.78 \\
\hline & Grip strength - Left & 1,469 & 50.1 & 24.5 & 1 & 112 & 829 & 33.8 & 15.9 & 3 & 70 & $<.001$ & 0.79 \\
\hline & Seated push-up test & 1,295 & 17.7 & 5.0 & 0 & 20 & 659 & 15.2 & 6.6 & 0 & 20 & $<.001$ & 0.43 \\
\hline \multirow[t]{5}{*}{$40-49 y$} & Timed sit to stand test & 61 & 20.7 & 8.2 & 10 & 50 & 41 & 20 & 4.9 & 11 & 33 & .632 & 0.10 \\
\hline & Sit-up test & 2,141 & 21.7 & 5.4 & 0 & 25 & 1,135 & 20.8 & 6.0 & 0 & 25 & .003 & 0.16 \\
\hline & Grip strength - Right & 869 & 51.5 & 25.5 & 2 & 106 & 442 & 34.7 & 15.9 & 2 & 67 & $<.001$ & 0.79 \\
\hline & Grip strength - Left & 877 & 49.4 & 25.2 & 3 & 106 & 442 & 33.3 & 15.6 & 2 & 66 & $<.001$ & 0.77 \\
\hline & Seated push-up test & 724 & 17.2 & 5.5 & 0 & 20 & 296 & 14.2 & 7.2 & 0 & 20 & $<.001$ & 0.47 \\
\hline \multirow[t]{5}{*}{$50-59 y$} & Timed sit to stand test & 25 & 21.4 & 6.8 & 13 & 43 & 11 & 22.3 & 14.2 & 10 & 60 & .795 & 0.08 \\
\hline & Sit-up test & 689 & 20.2 & 6.5 & 0 & 25 & 460 & 20.7 & 6.2 & 0 & 25 & .401 & 0.08 \\
\hline & Grip strength - Right & 275 & 46.3 & 23.0 & 2 & 99 & 203 & 33.5 & 15.1 & 1 & 60 & $<.001$ & 0.66 \\
\hline & Grip strength - Left & 271 & 44.0 & 22.2 & 2 & 98 & 206 & 33.1 & 14.8 & 3 & 60 & $<.001$ & 0.58 \\
\hline & Seated push-up test & 194 & 15.5 & 6.9 & 0 & 20 & 119 & 12.4 & 7.8 & 0 & 20 & $<.001$ & 0.42 \\
\hline \multirow[t]{5}{*}{$60-69 y$} & Timed sit to stand test & 9 & 23.3 & 13.1 & 11 & 50 & 0 & & & & & - & - \\
\hline & Sit-up test & 166 & 18.3 & 7.3 & 0 & 25 & 108 & 19.1 & 7.0 & 0 & 25 & .185 & 0.11 \\
\hline & Grip strength - Right & 94 & 40.6 & 20.0 & 8 & 88 & 46 & 31.7 & 15.0 & 1 & 60 & .008 & 0.50 \\
\hline & Grip strength - Left & 91 & 40.2 & 21.5 & 2 & 99 & 48 & 31.1 & 13.3 & 1 & 50 & .008 & 0.51 \\
\hline & Seated push-up test & 56 & 14.2 & 7.1 & 1 & 20 & 27 & 11 & 8.9 & 0 & 20 & .075 & 0.40 \\
\hline
\end{tabular}


Table 2. Pairwise age-band comparisons in the test scores (post hoc Fisher-Hayter pairwise comparisons) and proportion (P-value from chi-squared test) of Special Olympics athletes referred for education (Ref Ed).

\begin{tabular}{|c|c|c|c|c|c|c|c|c|c|c|c|c|c|c|c|c|}
\hline \multirow{4}{*}{ Gender } & & & \multicolumn{3}{|c|}{ Timed Sit to Stand } & \multicolumn{3}{|c|}{ Partial Sit-Up } & \multicolumn{5}{|c|}{ Grip Strength } & \multicolumn{3}{|c|}{ Seated Push-up } \\
\hline & \multicolumn{2}{|c|}{ Comparison } & \multicolumn{2}{|c|}{ FH-test } & \multirow[t]{2}{*}{ Ref Ed } & \multirow{2}{*}{\multicolumn{2}{|c|}{$\begin{array}{l}\text { FH-test } \\
\text { Criterion }\end{array}$}} & \multirow[t]{2}{*}{ Ref Ed } & \multicolumn{2}{|c|}{ FH-test - Right } & \multicolumn{2}{|c|}{ FH-test - Left } & \multirow[t]{2}{*}{ Ref Ed } & \multirow{2}{*}{$\begin{array}{l}\text { FH-test } \\
\text { Criterion }\end{array}$} & \multirow{2}{*}{\multicolumn{2}{|c|}{ Ref Ed }} \\
\hline & Cat1 & Cat2 & Criterion & & & & & & Criterion & & Criterion & & & & & \\
\hline & & & $=3.641$ & Sig. & $\mathrm{P}$ & $=3.634$ & Sig. & $\mathrm{P}$ & $=3.634$ & Sig. & $=3.634$ & Sig. & $\mathrm{P}$ & $=3.634$ & Sig. & $\mathrm{P}$ \\
\hline \multirow[t]{12}{*}{ Male } & $20-29 y$ & $30-39 y$ & 2.67 & & .060 & 3.75 & $\neq$ & $<.001$ & 0.46 & & 0.17 & & $<.001$ & 5.22 & $\neq$ & .036 \\
\hline & $20-29 y$ & $40-49 y$ & 5.63 & $\neq$ & .008 & 9.99 & $\neq$ & $<.001$ & 0.60 & & 1.04 & & $<.001$ & 7.57 & $\neq$ & .004 \\
\hline & $20-29 y$ & $50-59 y$ & 4.48 & ‡ & .025 & 14.00 & $\neq$ & $<.001$ & 5.17 & $\neq$ & 5.62 & $\neq$ & $<.001$ & 11.10 & $\neq$ & .002 \\
\hline & $20-29 y$ & $60-69 y$ & 4.08 & $\neq$ & .409 & 12.89 & $\neq$ & $<.001$ & 6.24 & $\neq$ & 5.40 & $\neq$ & .008 & 8.73 & $\neq$ & $<.001$ \\
\hline & $30-39 y$ & $40-49 y$ & 3.67 & $\neq$ & .212 & 6.23 & $\neq$ & $<.001$ & 0.20 & & 1.04 & & .001 & 3.01 & & .320 \\
\hline & $30-39 y$ & $50-59 y$ & 3.26 & & .202 & 11.63 & $\neq$ & $<.001$ & 4.70 & $\neq$ & 5.44 & $\neq$ & .093 & 8.43 & $\neq$ & .059 \\
\hline & $30-39 y$ & $60-69 y$ & 3.37 & & .712 & 11.82 & $\neq$ & $<.001$ & 5.99 & $\neq$ & 5.36 & $\neq$ & .117 & 7.36 & $\neq$ & .001 \\
\hline & $40-49 y$ & $50-59 y$ & 0.65 & & .732 & 7.15 & $\neq$ & $<.001$ & 4.35 & $\neq$ & 4.53 & $\neq$ & .699 & 6.30 & $\neq$ & .262 \\
\hline & $40-49 y$ & $60-69 y$ & 1.71 & & .873 & 9.54 & $\neq$ & $<.001$ & 5.79 & $\neq$ & 4.85 & $\neq$ & .774 & 6.24 & $\neq$ & .004 \\
\hline & $50-59 y$ & $60-69 y$ & 1.17 & & .724 & 5.27 & $\neq$ & .004 & 2.75 & & 1.81 & & .629 & 2.34 & & .056 \\
\hline & & & Criterion & & & Criterion & & & Criterion & & Criterion & & & Criterion & & \\
\hline & & & $=3.647$ & & & $=3.634$ & & & $=3.635$ & & $=3.635$ & & & $=3.636$ & & \\
\hline \multirow[t]{10}{*}{ Female } & $20-29 y$ & $30-39 y$ & 0.68 & & .141 & 0.00 & & .019 & 3.24 & & 2.11 & & .210 & 4.63 & $\neq$ & .436 \\
\hline & $20-29 y$ & $40-49 y$ & 0.74 & & .789 & 4.11 & $\neq$ & $<.001$ & 1.39 & & 0.77 & & .039 & 6.91 & $\neq$ & .862 \\
\hline & $20-29 y$ & $50-59 y$ & 1.90 & & .746 & 4.41 & $\neq$ & $<.001$ & 0.51 & & 0.40 & & .005 & 8.67 & $\neq$ & .439 \\
\hline & $20-29 y$ & $60-69 y$ & - & & - & 5.35 & $\neq$ & $<.001$ & 1.35 & & 1.12 & & .087 & 5.85 & $\neq$ & .893 \\
\hline & $30-39 y$ & $40-49 y$ & 0.30 & & .267 & 3.70 & $\neq$ & $<.001$ & 1.06 & & 0.81 & & .321 & 3.19 & & .690 \\
\hline & $30-39 y$ & $50-59 y$ & 1.64 & & .572 & 4.18 & $\neq$ & .021 & 2.22 & & 0.76 & & .039 & 6.12 & $\neq$ & .749 \\
\hline & $30-39 y$ & $60-69 y$ & - & & - & 5.28 & $\neq$ & .002 & 2.23 & & 1.69 & & .154 & 4.69 & $\neq$ & .932 \\
\hline & $40-49 y$ & $50-59 y$ & 1.36 & & .651 & 1.43 & & .541 & 1.32 & & 0.13 & & .205 & 3.56 & & .569 \\
\hline & $40-49 y$ & $60-69 y$ & - & & - & 3.82 & $\neq$ & .140 & 1.78 & & 1.34 & & .290 & 3.47 & & .945 \\
\hline & $50-59 y$ & $60-69 y$ & - & & - & 2.85 & & .088 & 1.00 & & 1.20 & & .704 & 1.46 & & .816 \\
\hline
\end{tabular}

Note: FH-test $=$ Fisher-Hayter pairwise comparison test with q set at $0.05 . \neq=$ values above the criterion value. 
To determine whether the proportion of SOI participants referred for education differed by age band, a series of $2 \times 2$ chi-square test of independence analyses were conducted. The outcome of each sex-based pairwise comparison of rates of referral has been presented in Table 3. Among the men, the rate of referral for the timed sit to stand test and the seated push-up test was generally higher among those 40+ years. Although the rate of referral for the partial sit-ups test increased with age, referral for grip strength decreased with age. Similar to the men, the rate of referral for education for the partial sit-up test increased steadily with age among the women. However, contrasting with the men, the rate of referral for education for the timed sit to stand test and grip strength did not differ by age band, and referral for the seated push-up test decreased with age.

Table 3. Proportion of men and women referred for education for each screen test and chi-squared comparison results.

\begin{tabular}{|c|c|c|c|c|c|c|}
\hline \multirow[t]{2}{*}{ Test, age, (n screened) } & \multicolumn{2}{|c|}{ Male } & \multicolumn{2}{|c|}{ Female } & \multirow[b]{2}{*}{$\mathrm{p}$} & \multirow[b]{2}{*}{$V$} \\
\hline & $\%$ & $\mathrm{~N}$ & $\%$ & $\mathrm{~N}$ & & \\
\hline \multicolumn{7}{|l|}{ Timed sit to stand test } \\
\hline All $(n=1,264)$ & 24.5 & 202 & 33.6 & 147 & .001 & .097 \\
\hline $20-29 y(n=788)$ & 21.1 & 113 & 31.4 & 79 & .002 & .112 \\
\hline $30-39 y(n=329)$ & 27.7 & 54 & 38.8 & 52 & .034 & .117 \\
\hline $40-49 y(n=102)$ & 36.1 & 22 & 29.3 & 12 & .475 & .071 \\
\hline $50-59 y(n=36)$ & 40.0 & 10 & 36.4 & 4 & .837 & .034 \\
\hline $60-69 y(n=9)$ & 33.3 & 3 & - & - & - & \\
\hline \multicolumn{7}{|l|}{ Partial sit-up test } \\
\hline All $(n=24,150)$ & 30.5 & 4,781 & 37.8 & 3,211 & $<.001$ & .074 \\
\hline $20-29 y(n=13,492)$ & 26.3 & 2,319 & 35.0 & 1,633 & $<.001$ & .091 \\
\hline $30-39 y(n=5,959)$ & 31.1 & 1,191 & 37.9 & 805 & $<.001$ & .070 \\
\hline $40-49 y(n=3,276)$ & 38.3 & 820 & 45.4 & 515 & $<.001$ & .069 \\
\hline $50-59$ y $(n=1,149)$ & 50.4 & 347 & 43.7 & 201 & .027 & .065 \\
\hline $60-69 y(n=274)$ & 62.7 & 104 & 52.8 & 57 & .105 & .098 \\
\hline \multicolumn{7}{|l|}{ Grip strength test } \\
\hline All $(n=10,025)$ & 43.9 & 2,866 & 19.9 & 696 & $<.001$ & .240 \\
\hline $20-29 y(n=5,603)$ & 47.6 & 1,762 & 21.6 & 411 & $<.001$ & .252 \\
\hline $30-39 y(n=2,387)$ & 42.1 & 643 & 19.5 & 168 & $<.001$ & .229 \\
\hline $40-49 y(n=1,381)$ & 35.5 & 324 & 17.3 & 81 & $<.001$ & .189 \\
\hline $50-59 y(n=505)$ & 36.8 & 104 & 13.5 & 30 & $<.001$ & .261 \\
\hline $60-69 y(n=149)$ & 34.0 & 33 & 11.5 & 6 & .003 & .238 \\
\hline \multicolumn{7}{|l|}{ Seated push-up test } \\
\hline All $(n=27,905)$ & 6.3 & 1,131 & 10.5 & 1,051 & $<.001$ & .081 \\
\hline $20-29 y(n=15,215)$ & 5.8 & 569 & 10.4 & 557 & $<.001$ & .091 \\
\hline $30-39 y(n=6,852)$ & 6.6 & 288 & 10.9 & 273 & $<.001$ & .082 \\
\hline $40-49 y(n=3,914)$ & 7.1 & 179 & 10.1 & 141 & .001 & .061 \\
\hline $50-59$ y $(n=1,520)$ & 7.8 & 68 & 10.1 & 65 & .116 & .054 \\
\hline $60-69 y(n=404)$ & 11.0 & 27 & 9.4 & 15 & .610 & .030 \\
\hline
\end{tabular}

\section{Discussion}

\section{Age-related differences}

The first hypothesis, that strength would decrease with age, was generally supported. Men showed statistically significant age-related decline in all four strength variables, although the trend for timed sit to stand test scores was less consistent. Men in the two youngest age-bands had faster timed sit to stand scores compared to older men, but this appeared to plateau from 40 years of age onward. Women also displayed significant agerelated declines in partial sit-up and seated push-up, but not for timed sit to stand or grip strength. Although the proportion of men and women referred for education related to the 
seated push-up was relatively small (5.8 - 11.0\% for men and $9.4-10.9 \%$ for women), it is important to note that the cut-off for referral (5 second body support) has clinical significance in terms of preventing ulcers by relieving pressure on the skin (Kosiak \& Kottke, 1990). This may become increasingly important as the athletes increase in age.

The findings for the timed sit to stand test in this study contrast somewhat with timed sit to stand scores established among healthy individuals screened for systemic disease (symptomatic arthritis, severe obstructive lung disease, symptomatic angina, uncompensated congestive heart failure, morbid obesity, or other systemic disease), where there is a consistent age-related decline (Csuka \& McCarty, 1985). The lack of a consistent age-related decline in this study may, in part, reflect the large difference in actual times between the Csuka and McCarty study and the present study. For example, times for males aged 20 - 30 years old in the Csuka and McCarty study ranged from 8.8 - 10.8 seconds, whereas the mean time for men from SOI HAS, in the present study, aged $20-29$ years was 17.4 seconds. Thus, it is perhaps not surprising that approximately one-quarter of the men and one-third of the women in the younger age bands were referred for education because their performance on the timed sit to stand test was greater than 20 seconds. Additionally, age-related decreases in the timed sit to stand test performance were observed among the men, particularly comparing the youngest age band (20 - 29y) with the two oldest age bands (50 - 59y and 6o-69y). Although the trend among women was for poorer performance on the timed sit to stand test with age, these differences were not statistically significant, additionally there were no women in the oldest age band of $60-69$ years old for this test.

Compared to multinational grip strength normative values for the general population derived from 12 studies in 5 countries (Bohannon et al., 2006), men in this global sample of Special Olympics athletes had generally comparable age-related scores. However, the agerelated decline in grip strength seen in the female general population and among adults with ID (Bohannon et al., 2006; Cuesta-Vargas \& Hilgenkamp, 2015) was not evident among the women in this study. Because the Special Olympics women's grip strength scores across the age bands was relatively stable, but the multinational normative grip strength scores declined with age, there was divergence in grip strength among the two oldest age bands. In other words, among women aged $60-69$ years, the difference was approximately $5 \mathrm{kgs}$ in favour of the Special Olympics athletes. It is possible this represents a positive outcome of engaging in sports as women age or that women who are stronger at an older age continue to play sport. The proportion of women referred for education for grip strength in this study was relatively low compared to rates of referral related for the timed sit to stand and partial sit-up scores. These findings suggest that in this global sample of female Special Olympics athletes, hand and forearm strength were quite high. Considerably higher compared to a sample of $n=801$ Spanish Special Olympics athletes (Cuesta-Vargas \& Hilgenkamp, 2015) for both men and women in comparable age bands. It is possible that the inclusion of participants across a range of country economic statuses influenced this finding. Santarossa and colleagues (2017) found that female Special Olympics athletes from low-income and high-income had statistically significantly higher grip strength scores than Special Olympics athletes from lower- and upper middle income countries. This may reflect the structure of household and work-related tasks requiring grip and upper body strength that participants engaged in differing levels of economy (Popkin, 2002), it may reflect differing access to strength and conditioning activities in countries included in this sample, or both of those factors.

Abdominal muscle strength as assessed by the partial sit-up test in this study showed a small, but steady and significant, decline with increasing age for both men and women along with high rates of referral for education. This is of particular concern, as lower trunk muscle 
strength is associated with poor balance and functional performance, and a higher rate of falls in older adults (Granacher et al., 2013) and reduced athletic functioning (Kibler et al., 2006). Importantly, trunk muscle strength can be improved considerably with core strength training (Granacher et al., 2013). Therefore, the identification of the need for intervention through this screening and the associated high rates of referral has the potential to favourable impact important health outcomes. However, we do not know whether there was follow-through on these referrals or whether there were subsequent improvements in core muscle strength. Additional follow-up and applied research on the effect of referrals on local level Special Olympics Programs and families are needed.

\section{Sex-based differences}

Our second hypothesis was that men would be stronger than women. On the whole, this hypothesis was supported, particularly within the younger age bands. All of the strength measures were higher for men in the youngest two age bands. In addition, partial sit-up, grip strength, and seated push-up scores were statistically significantly higher for men in the next age band (i.e., $40-49$ years), and this trend continued for partial sit-up and grip strength to $50-59$ years, and for the oldest age-band for grip strength. It appears that there is some convergence in the strength scores between men and women with increasing age.

In the general population timed sit to stand scores for men are uniformly faster than for women (Csuka \& McCarty, 1985). In our study, this type of sex-related difference was only evident for Special Olympics athletes aged 39 years old and younger for the timed sit to stand test, and for partial sit-up, younger than 50 years of age. Similar to other research with the general population (Bohannon et al., 2006) and with individuals with ID (Cuesta-Vargas \& Hilgenkamp, 2015), men had higher grip strength scores than women. The actual scores for women in this study appear to be much higher when compared with younger Special Olympics athletes from Spain (Cuesta-Vargas \& Hilgenkamp, 2015), older adults with ID from the Netherlands (50 - 59y and 6o - 69y) (Cuesta-Vargas \& Hilgenkamp, 2015), and older adults residing in residential care centre in Israel (Carmeli et al., 2012). Relatedly, despite having statistically significantly and substantially lower grip strength scores compared to male Special Olympics athletes, women were less often referred for education for poor grip strength. It would be useful to examine whether the women's grip strength scores, which appear to be relatively positive compared to other women, are functionally relevant in terms of performing household and work-related tasks and sports activities. This would also inform Special Olympics about whether the cut-off point for referral for education for women is adequate.

\section{Limitations and future directions}

This study was delimited to the SOI HAS database. Along with study strengths, such as the large sample size and directly measured strength, comes several limitations. Foremost, information such as the etiology of ID, levels of support needed, medication use, comorbidities, associated health conditions, and living, working, and fitness training arrangements were not part of the available FUNfitness data. Therefore, we were not able to examine interactions between these factors or potential explanations of patterns that we observed. Individual's health behaviours and outcomes do not exist in a vacuum (Cottrell et al., 2018), and consideration of the larger social system of influences on functional strength is important for future research. In addition, although the validity of the test items and reference values for comparisons with functional and health outcomes has been examined to some extent, further validation work is warranted. Concurrent validation of each measure in the test battery across many demographics (e.g., sex, age, ethnicity, and etiology) and any effect of using different handgrip dynamometers for grip strength would be valuable. 
Recently, Oppewal and Hilgenkamp (2020) published a conceptual paper with ideas for a fitness test battery for older adults with ID based on what is already validated. A conceptual synthesis and critique of strength measures suitable for the breadth of Special Olympics community would be useful. Recently, Van Bisen and Pineda examined the test-retest reliability of Special Olympics FUNfitness strength and balance items and found that these measures "demonstrated good test-retest reliability, stable responsiveness, no differences between test and retest performance, and no major systematic bias" (Van Biesen \& Pineda, 2019, p. 5) when examined in standardized conditions. However, it would be valuable for Special Olympics and the research community to establish the efficacy of the current training on volunteers' abilities to accurately and reliably administer the FUNfitness test battery in less standardized contexts.

\section{Perspectives}

As hypothesized, males were stronger than females, muscular strength generally decreased with age, and the rate of referral for education increased with age. Compared with published data for individuals without an ID, grip strength scores were similar, but timed sit to stand and sit-up scores were low. Poor abdominal and leg strength are associated with adverse health and functional outcomes. These outcomes include difficulty walking and taking the stairs, poor balance and increased risk of falls, and back pain. As with the general population, individuals with an ID need good muscular strength as a component of their health-related fitness; with special attention to falls prevention. This study shows that the Special Olympics Healthy Athletes screenings identified individuals with low strength. What we do not know is whether there was follow-up at the local level or whether there was associated intervention to improve aspects of muscular strength. This is important because strength is a modifiable aspect of physical health for all ages.

\footnotetext{
Author affiliations:

1 School of Exercise Science, Physical and Health Education, University of Victoria, Canada; vtemple@uvic.ca; shayzeitzo8@gmail.com

2 Faculty of Sport and Health Sciences, University of Jyväskylä, Finland; pauli.rintala@jyu.fi

3 Faculty of Health Sciences, Ontario Tech University, Canada; Meghann.Lloyd@uoit.ca

4 Physical Education Department, State University of New York College at Cortland, USA; John.Foley@cortland.edu

* Correspondence: vtemple@uvic.ca; Tel.: +1-250-721-7846
}

Author Contributions: Conceptualization, V.T., P.R., M.L., and J.F.; Methodology, V.T., P.R., M.L., and J.F.; Formal Analysis, J.F.; Writing-Original Draft Preparation, V.T., P.R, S.Z.; Writing-Review \& Editing, V.T., P.R., S.Z., M.L., and J.F.

Funding: This research received no external funding.

Acknowledgments: Healthy Athletes data collection was supported by cooperative agreement \#5U59DDo00995 from the US Centers for Disease Control and Prevention and a grant from the Golisano Foundation, USA. We wish to thank Special Olympics International for their support and also like to thank all of the Special Olympics athletes for their participation. Details of how to initiate a FUNfitness screening event and connect with a trained Clinical Director who hosts the screening is available at https://media.specialolympics.org/resources/health/disciplines/funfitness/FUNfitness-Training-ManualSeptember-2020.pdf? ga=2.145393137.496194287.1599068593-809420616.1543326948.

Conflicts of Interest: The authors declare no conflict of interest.

\section{References}

Anderson, D. S., Jackson, M. F., Kropf, D. S., \& Soderberg, G. L. (1984). Electromyographic analysis of selected muscles during sitting push-ups: Effects of position and sex.

Physical Therapy, 64(1), 24-28. https://doi.org/10.1093/ptj/64.1.24

Bohannon, R. W., Peolsson, A., Massy-Westropp, N., Desrosiers, J., \& Bear-Lehman, J. (2006). Reference values for adult grip strength measured with a Jamar dynamometer: A descriptive meta-analysis. Physiotherapy, 92(1), 11-15.

https://doi.org/10.1016/j.physio.2005.05.003 
Bohannon, R. W., Shove, M. E., Barreca, S. R., Masters, L. M., \& Sigouin, C. S. (2007). Five-repetition sit-to-stand test performance by community-dwelling adults: A preliminary investigation of times, determinants, and relationship with self-reported physical performance. Isokinetics and Exercise Science, 15, 77-81. https://doi.org/10.3233/IES-2007-0253

Carmeli, E., Imam, B., \& Merrick, J. (2012). The relationship of pre-sarcopenia (low muscle mass) and sarcopenia (loss of muscle strength) with functional decline in individuals with intellectual disability (ID). Archives of Gerontology \& Geriatrics, 55(1), 181-185. https://doi.org/10.1016/j.archger.2011.06.032

Cottrell, R. R., Girvan, J. T., Seabert, J. T., Caile, S., \& McKenzie, J. F. (2018). Principles and Foundations of Health Promotion and Education (7 ed.). Pearson.

Cowley, P. M., Ploutz-Snyder, L. L., Baynard, T., Heffernan, K., Jae, S. Y., Hsu, S., Lee, M., Pitetti, K. H., Reiman, M. P., \& Fernhall, B. (2010). Physical fitness predicts functional tasks in individuals with Down syndrome. Medicine and Science in Sports and Exercise, 42, 388-393. https://doi.org/10.1249/MSS.obo13e3181bo7e7a

Cox, C. R., Clemson, L., Stancliffe, R. J., Durvasula, S., \& Sherrington, C. (2010). Incidence of and risk factors for falls among adults with an intellectual disability. Journal of Intellectual Disability Research, 54(12), 1045-1057. https://doi.org/10.1111/j.13652788.2010.01333.X

Csuka, M., \& McCarty, D. J. (1985). Simple method for measurement of lower extremity muscle strength. The American Journal of Medicine, 78, 77-81. https://doi.org/10.1016/0002-9343(85)90465-6

Cuesta-Vargas, A. I., \& Hilgenkamp, T. (2015). Reference values of grip strength measured with a Jamar dynamometer in 1526 adults with intellectual disabilities and compared to adults without intellectual disability. PLOS ONE, 1O(6), 1-10. https://doi.org/10.1371/journal.pone.0129585

Cuesta-Vargas, A. I., Paz-Lourido, B., \& Rodriguez, A. (2011, Mar-Apr). Physical fitness profile in adults with intellectual disabilities: Differences between levels of sport practice. Research in Developmental Disabilities 32(2), 788-794. https://doi.org/10.1016/j.ridd.2010.10.023

Foley, J. T., Lloyd, M., \& Temple, V. A. (2013). Body mass index trends among adult U.S. Special Olympians, 2005-2010. Adapted Physical Activity Quarterly, 3o(4), 373-386. https://doi.org/10.1123/apaq.30.4.373

Franciosi, E., Baldari, C., Gallotta, M. C., Emerenziani, G. P., \& Guidetti, L. (2010). Selected factors correlated to athletic performance in adults with mental retardation. Journal of Strength and Conditioning Research, 24(4), 1059-1064. https://doi.org/10.1519/JSC.obo13e3181ca503c

Franciosi, E., Guidetti, L., Gallotta, M. C., Emerenziani, G. P., \& Baldari, C. (2010). Contributions of selected fundamental factors to basketball performance in adult players with mental retardation. Journal of Strength and Conditioning Research, 24(8), 2166-2171. https://doi.org/10.1519/JSC.obo13e3181e34754

Granacher, U., Gollhofer, A., Hortobágyi, T., Kressig, R. W., \& Muehlbauer, T. (2013). The importance of trunk muscle strength for balance, functional performance, and fall prevention in seniors: A systematic review. Sports Medicine, 43(7), 627-641. https://doi.org/10.1007/s40279-013-0041-1

Hilgenkamp, T. I., van Wijck, R., \& Evenhuis, H. M. (2012). Feasibility and reliability of physical fitness tests in older adults with intellectual disability: A pilot study. Journal of Intellectual and Developmental Disability, 37(2), 158-162. https://doi.org/10.3109/13668250.2012.681773

Innes, E. (1999). Handgrip strength testing: A review of the literature. Australian Occupational Therapy Journal, 46(3), 120-140. https://doi.org/10.1046/j.14401630.1999.00182.X

Ishigaki, E. Y., Ramos, L. G., Carvalho, E. S., \& Lunardi, A. C. (2014). Effectiveness of muscle strengthening and description of protocols for preventing falls in the elderly: A systematic review. Brazilian Journal of Physical Therapy, 18, 111-118.

https://doi.org/10.1590/S1413-35552012005000148 
Kibler, W. B., Press, J., \& Sciascia, A. (2006). The role of core stability in athletic function. Sports Medicine, 36(3), 189-198. https://doi.org/10.2165/00007256-200636030O0001

Kirk, R. E. (2013). Multiple comparison tests (4 ed.). SAGE Publications, Inc. https://doi.org/10.4135/9781483384733

Kosiak, M., \& Kottke, F. J. (1990). Prevention and rehabilitation of ischemic ulcers. In F. J. K. F. H. Krusen, \& J. F. Lehmann (Ed.), Krusen's Handbook of Physical Medicine and Rehabilitation (4 ed., pp. 976-987). WB Saunders.

Kuh, D., Bassey, E. J., Butterworth, S., Hardy, R., Wadsworth, M. E. J., \& Team, a. t. M. S. (2005). Grip strength, postural control, and functional leg power in a representative cohort of British men and women: Associations with physical activity, health status, and socioeconomic conditions. The Journals of Gerontology Series A: Biological Sciences and Medical Sciences, 6o(2), 224-231. https://doi.org/10.1093/gerona/60.2.224

Lahtinen, U., Rintala, P., \& Malin, A. (2007). Physical performance of individuals with intellectual disability: A 30-year follow-up. Adapted Physical Activity Quarterly, 24(2), 125-143. https://doi.org/10.1123/apaq.24.2.125

Newcomer, K. L., Krug, H. E., \& Mahowald, M. L. (1993). Validity and reliability of the timed-stands test for patients with rheumatoid arthritis and other chronic diseases. The Journal of Rheumatology, 2O(1), 21-27.

Nordgren, B., \& Bäckström, L. (1971). Correlations between muscular strength and industrial work performance in mentally retarded persons. Acta Paediatrica Scandinavica. Supplement, 217, 122-126.

Oppewal, A., \& Hilgenkamp, T. I. M. (2020). Adding meaning to physical fitness test results in individuals with intellectual disabilities. Disability \& Rehabilitation, 42(10), 1406-1413. https://doi.org/10.1080/09638288.2018.1527399

Oppewal, A., Hilgenkamp, T. I. M., van Wijck, R., Schoufour, J. D., \& Evenhuis, H. M. (2014a). Physical fitness is predictive for a decline in daily functioning in older adults with intellectual disabilities: Results of the HA-ID study. Research in Developmental Disabilities, 35(10), 2299-2315. https://doi.org/10.1016/j.ridd.2014.05.027

Oppewal, A., Hilgenkamp, T. I. M., van Wijck, R., Schoufour, J. D., \& Evenhuis, H. M. (2014b). The predictive value of physical fitness for falls in older adults with intellectual disabilities. Research in Developmental Disabilities, 35(6), 1317-1325. https://doi.org/http://dx.doi.org/10.1016/j.ridd.2014.03.022

Oppewal, A., Hilgenkamp, T. I. M., van Wijck, R., Schoufour, J. D., \& Evenhuis, H. M. (2015). Physical fitness is predictive for a decline in the ability to perform instrumental activities of daily living in older adults with intellectual disabilities: Results of the HAID study. Research in Developmental Disabilities, 41-42, 76-85. https://doi.org/10.1016/j.ridd.2015.05.002

Parfrey, K. C., Docherty, D., Workman, R. C., \& Behm, D. G. (2008, Oct). The effects of different sit- and curl-up positions on activation of abdominal and hip flexor musculature. Applied Physiology, Nutrition, and Metabolism 33(5), 888-895. https://doi.org/10.1139/ho8-061

Popkin, B. M. (2002). Part II. What is unique about the experience in lower-and middleincome less-industrialised countries compared with the very-highincome industrialised countries?: The shift in stages of the nutrition transition in the developing world differes from past experiences! . Public Health Nutrition, 5(1a), 205214. https://doi.org/10.1079/PHN2001295

Rintala, P., Asunta, P., Lahti, J., \& Loovis, M. (2016). Physical fitness of individuals with an intellectual disability who have special Olympics experience. European Journal of Adapted Physical Activity, 9(2), 13-19. https://doi.org/10.5507/euj.2016.006

Roldán-Jiménez, C., Bennett, P., \& Cuesta-Vargas, A. I. (2015). Muscular activity and fatigue in lower-limb and trunk muscles during different sit-to-stand tests. PLoS ONE, 1O(10), e0141675. https://doi.org/10.1371/journal.pone.0141675

Salb, J., Finlayson, J., Almutaseb, S., Scharfenberg, B., Becker, C., Sieber, C., \& Freiberger, E. (2015). Test-retest reliability and agreement of physical fall risk assessment tools in 
adults with intellectual disabilities. Journal of Intellectual Disability Research, 59(12), 1121-1129. https://doi.org/10.1111/jir.12216

Santarossa, S., Temple, A. V., Rintala, P., Lloyd, M., DeMarco, B., \& Foley, T. J. (2017). Muscular strength of adult Special Olympians by country economic status. European Journal of Adapted Physical Activity, 10(1), 10-16. https://doi.org/10.5507/euj.2017.002

Short, F. X., \& Winnick, J. P. (2005). Test Items and Standards Related to Muscle Strength and Endurance on the Brockport Physical Fitness Test. Kinesiology, Sport Studies and Physical Education Faculty Publications, Paper 3, 1-32.

http://digitalcommons.brockport.edu/pes facpub/3

Special Olympics. (2016). Special Olympics global strategic plan 2016 - 2020.

http://media.specialolympics.org/resources/strategic-plan/Special-Olympics-GlobalStrategic-Plan---2016-2020.pdf

Special Olympics. (2020a). Our Work: Healthy Athletes.

https://www.specialolympics.org/our-work/inclusive-health/healthy-athletes

Special Olympics. (2020b). Special Olympics FUNfitness. FUNfitness: Learn how to organize, promote and present.

http://media.specialolympics.org/resources/health/disciplines/funfitness/FUNfitness -Training-Manual.pdf

Stata Corp. (2017). Stata Statistical Software: Release 15. In StataCorp LLC.

Taekema, D. G., Gussekloo, J., Maier, A. B., Westendorp, R. G. J., \& de Craen, A. J. M. (2010). Handgrip strength as a predictor of functional, psychological and social health. A prospective population-based study among the oldest old. Age Ageing, 39(3), 331337. https://doi.org/10.1093/ageing/afq022

Van Biesen, D., \& Pineda, C. R. (2019). Balance and strength assessment of Special Olympics athletes: How feasible and reliable is the Fun Fitness test battery? European Journal of Adapted Physical Activity, 12(1), 6-6. https://doi.org/10.5507/euj.2019.004

Winnick, J. P., \& Short, F. X. (1998). Project Target: Criterion-referenced physical fitness standards for adolescents with disabilities final report. U. S. D. o. E. Office of Special Education and Rehabilitative Services.

Winnick, J. P., \& Short, F. X. (2014). Brockport physical fitness test manual. A healthrelated assessment for youngsters with disabilities (2nd ed.). Human Kinetics.

World Health Organization. (2020). WHO guidelines on physical activity and sedentary behaviour. https://www.who.int/publications/i/item/9789240015128

Yun, J., Agiovlasitis, S., \& Bryan, R. (2007). Reliability of muscular strength and endurance assessments for individuals with mental retardation using generalizability theory. Research Quarterly for Exercise \& Sport, 78(1), A-105.

(C) 2022 by the authors. Submitted for possible open access publication under the terms and conditions of the Creative Commons Attribution (CC BY) license (http://creativecommons.org/licenses/by/4.o/). 